\title{
Factors that Generate Labor Commitment in the Human Capital of an Institution of Higher Education
}

\author{
José de Jesús Hernández Sánchez ${ }^{1}$, Dra. Josefina Morgan Beltrán ${ }^{2 *}$, M.A. Martha July Mora \\ Haro $^{3}$ \\ ${ }^{1}$ Bachelor of Administration, UAQ academic mobility coordinator, undergraduate professor (442) 1589319, \\ ${ }^{2}$ Doctor of Administration and research professor at the Autonomous University of Querétaro, MEXICO. \\ Belonging to SIN 1, ORC ID: 0000-0002-6338-6209 \\ ${ }^{3}$ Public Accountant, master's degree in Administration, specialty in international business, free time teacher at \\ the UAQ telephone 4423943667
}

\begin{abstract}
*Corresponding Authors: Dra. Josefina Morgan Beltrán, Doctor of Administration and research professor at the Autonomous University of Querétaro, MEXICO. Belonging to SIN 1, ORC ID: 00000002-6338-6209
\end{abstract}

\begin{abstract}
The objective of this research is to determine if training is a factor for the administrative staff working in the HEIs to feel committed to their work, it is developed in a Higher Education Institution (HEI), the hypothesis states that there is a direct relationship of training with commitment, considering the questionnaire as a tool to detect the needs of workers in terms of their personal or professional training and if, as they develop, they feel more attached to the place where they work. The results mention that the workers know that they have complications in various aspects within their workplace that have not allowed them that growth, therefore 50\% of those interviewed mention not having a complete feeling of belonging. It is also detected that, despite the lack of training courses, many of them feel proud of the way in which they work, they do not discredit their efforts so that they are giving the results that are in their departmental objectives, taking into account the lack of equipment in some cases (knowing that their objectives are achieved), the pride of being part of this Institution is not lost.
\end{abstract}

Keywords: Labor commitment, Human Capital, Institutions of Higher Education (IES)

\section{INTRODUCTION}

The human being is a being endowed with many skills and knowledge, which he shares every day inside and outside of social circles. The current way of life requires opportunities for work, personal and educational growth; For this reason, the staff seeks training as one of its development alternatives which contributes to the generation of a decent work environment, this because with the new knowledge in technologies they must carry out new methods of continuous improvement in their daily work, which in the end will contribute to the individual's own growth.

The workplaces of people, in addition to being the place where they carry out a subordinate and remunerated activity as stated in the Federal Labor Law of the country, is also a place of daily coexistence, which allows the worker to generate certain senses of emotional affectation and mandatory to carry out their activities in a responsible manner, but at the same time create a sense of belonging that makes people feel committed to making the maximum effort, generating trust, respect, quality at work, etc.

The company does not do a good worker, but the courses and workshops collaborate a lot to be able to TRAIN in relation to the improvement of the aforementioned capacities and abilities that the individual possesses. Considering that the human being has so many capacities that he does not know himself, being able to take certain courses will allow those to evaluate new ones, confirm if he is suitable to change positions, which in the long run will benefit the parties, both the worker in a new position (even new company) and the organization, since it is improving the quality indicators and the growth of its employees. 
When the staff has been allowed to be developed both professionally, intellectually and in physical skills to improve both income and knowledge, or even better positions, this should be reflected in the existence of a work commitment in which at the end of the day it will be a win-win concept, both for the worker for new and better knowledge, as well as for the organization where the worker will present a motivation when presenting to their workplace that together with a comfortable work environment will present a commitment towards the institution that allows this growth.But in the same way there must be trust between the worker and the company. Since a person who knows that they trust her, she tries to do her best, and in the end, she succeeds.

\section{THEORETICAL FRAMEWORK}

\subsection{Professional Development}

Organizations seek to have the best personnel, who are efficient, who have the necessary and competitive skills that allow them to face the challenges that the labor market demands. Developing appropriate professional development models for staff to understand instructor content is challenging. The courses and workshops must present the tools of continuous improvement of these, in the same way allow workers, employees and collaborators to carry out these processes of personal and professional growth and development.

This is why the purpose of commitment must exist (not as a definition, but as an attitude and virtue) on the part of those who will be trained. The success of professional development being an agent of change in the needs of the organization, company or institution will be based on the staff feeling the desire for a change to occur that benefits the levels of this.

Also the existence of a motivational factor in organizations that go beyond the formal contracts of organizations (such as salary, benefits, etc.), is the way in which the employee is part of and feels identified. Achieving that this forms expectations by being a part, makes the individual trust to want to grow to continue within the institution.

By generating links with the company, organization or institution, the individual will feel, in addition to belonging, a symbol of reciprocity to that place of which he is a part, for which he will give more of himself to meet the expectations of the bosses and all the staff, but even more so.

The Theory of Human Capital: (Galván, 2011) It was developed by Gary Sanley Becker, its main idea is to consider education and training as investments made by rational individuals, in order to increase their productive efficiency and income. The Human Capital Theory considers that the economic agent (individual) has a rational behavior, invests for himself and that investment is made based on a calculation. On the other hand, this theory makes it possible to distinguish between general training and specific training. The first is acquired in the educational system as a student and is intended to increase the productivity of the individual (s). Specific training makes sense in the case of a durable employment relationship between the worker and the employer, there are two possibilities: the employer finances the investment or shares it with the worker

Siliceo (2006) refers that training is an activity planned and based on real needs of a company or organization and oriented towards a change in the knowledge, skills and attitudes of the collaborator.

Rodríguez (2010) explains that training is a specific and invaluable contribution to current organizations, training activities are located in mere professional activity, a company that trains its employees is on the way to professionalization.

Training is usually practical, humanistic, or technical and can be general or specific, while training is practical, technical, and is quite task-specific. With the two techniques, development is achieved that according to Rodríguez (2010) is the ability to deploy something that is rolled or rolled, in such a way that it can shine in all its fullness, both training and education in general base their success on the potential that the subjects have to learn and grow that of the instructors' purposes to instill and transmit the contents.

The nature and importance of the concept of training is shown through behavioral management models based on quality principles as proposed by Deming (1989) and Juran and Gryna (1994), and which have vindicated the role of workers in terms of their participation and training for the improvement of the organization's processes, and for one's own personal development. This has been verified by Masaaki (1990) with his continuous improvement methodology. Likewise, some elements 
of organizational learning are reviewed, such as culture and organizational design, and the way in which they affect training in the search for continuous organizational learning is analyzed.

The training and development process is a process of change. Thanks to him, mediocre employees are transformed into capable workers and current workers develop to fulfill new responsibilities. To verify the success of a program, personnel managers must insist on systemic evaluation of their activity. (Werther, at al., 2000, p.256).

\subsection{Organizational Commitment}

Organizational commitment encompasses different approaches, the Meyer and Allen theory and its three components of organizational commitment. Meyer and Allen (1997) identify:

1. affective commitment,

2. the commitment to stay and

3. the normative commitment,

Affective commitment refers to emotional attachment, identification and involvement with the organization, the commitment of permanence emphasizes the cost that it would represent for the individual to leave, leave the organization and the normative commitment refers to a feeling of obligation on the part of the individual to remain in the institution.

Commitment is considered as a mechanism that produces solid behaviors, which favor the development of people with consistent lines of activity, which they themselves chose to obtain their purposes. Likewise, commitment is understood as the totality of internalized normative pressures to act on a path that intersects with organizational interests (De Frutos, Ruiz \& San Martin, 1998).

The psychological interaction between employee and organization is a reciprocal process; the organization does certain things for the worker and for the worker, it pays them, gives them security and status; in the same way, the employee responds by working and performing her tasks. The organization expects the employee to heed its authority and, in turn, the employee expects the organization to comply with it and act fairly. The organization reinforces the expectation of him through the use of the authority and power available to him, while the employee reinforces the expectation of him through certain attempts to influence the organization or limit his participation. The two parts of the interaction are guided by guidelines that define what is right and fair and what is not. Some sociologists refer to a "norm of reciprocity," while some psychologists call this a "psychological contract." Every contract has two fundamental parts:

1. The formal and written contract. Agreement related to the position to be held, the content of the work, the schedule, the salary, etc.

2. The psychological contract. Expectation that the individual and the organization hope to meet and achieve with the new relationship.

This psychological contract refers to the mutual expectation of the individual and the organization, which extends beyond any formal employment contract that establishes the work to be done and the reward to be received. Although there is no formal or clearly express agreement, the psychological contract is a tacit agreement between the individual and the organization for the two parties to observe and respect a wide variety of rights, privileges and obligations enshrined by custom.

The psychological contract is an important element in any employment relationship and influences the behavior of the parties. A contract is a kind of agreement or expectation that people have with themselves and with others. Ultimately, each person represents her own contracts, which govern both interpersonal relationships and the relationships that she maintains with herself (interpersonal relationships).

People form or join an organization because they expect their participation to meet some personal needs. To obtain these satisfactions, people are willing to incur certain costs or make personal 
investments (efforts) in the organization, since they expect that the satisfaction of their personal needs will be greater than the costs, and they evaluate the degree of satisfaction expected and the costs through their value systems (Figure 2.1)

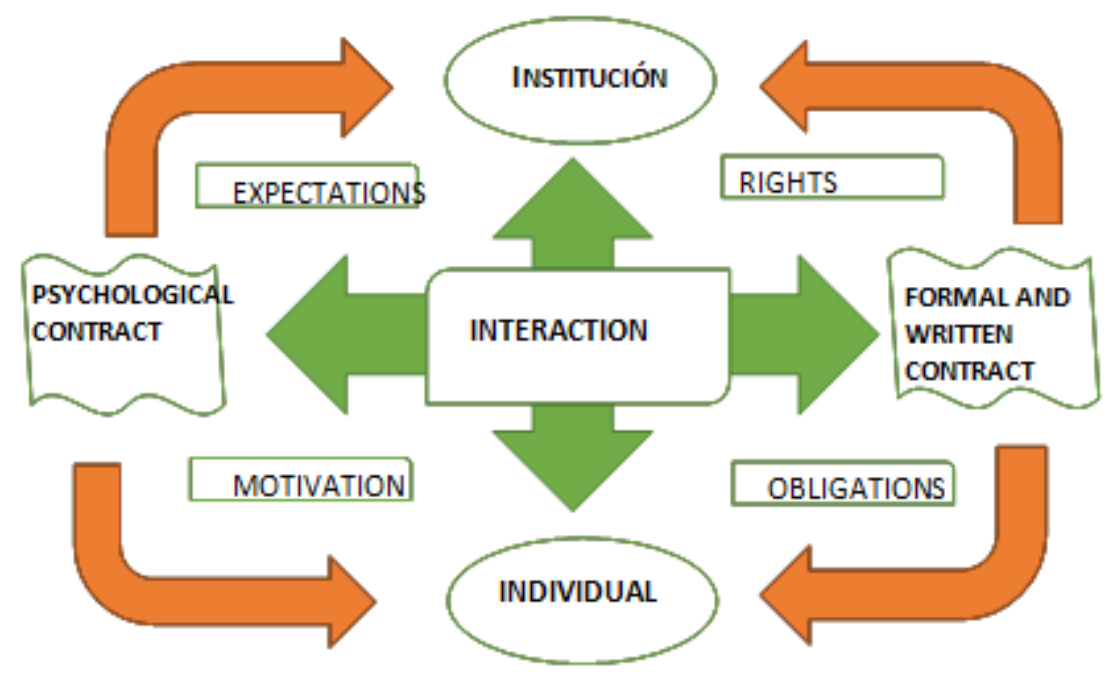

\section{Methodology}

Determining if there is a commitment on the part of all the personnel who work in the IES and if this commitment is linked to the fulfillment of the mission and vision is very important for the organization. The personnel working in the HEIs must have all the necessary skills and knowledge and in order to determine this, they must diagnose in the most appropriate way and detect deficiencies to try to compensate for said weaknesses, allowing employees to develop and integrate into the Institution and know what you are capable of.

Organizations must seek that their collaborators work out of conviction; For this, the environment and their productivity must be taken into account. Training, according to Martha Alles (2004), is the transmission of knowledge and skills; it is a process that must be organized, planned, and evaluable. The result of this aspect is the beginning to promote behavioral and organizational changes, evident in each worker, in order to maintain effective performance, and adapt to different ways of working, most of the members of the organization need to be trained, thus hoping that the expansion of skills occurs in a shorter time.

According to Sherman, "The rationale for training new hires is to give them the knowledge, skills, and abilities they require to perform successfully [...] additional training gives them the opportunity to acquire new knowledge and skills."

\subsection{Research Question}

Does training have a favorable impact on work commitment in the heis?

\subsection{General Purpose}

Identify the competencies and / or abilities that the HEI staff have in their corresponding departments

\subsection{Specific Objectives.}

- Establish a habit of commitment in the personnel on the training courses

- Rotate staff with the skills and / or abilities to the department with the corresponding needs.

\subsection{Definition of the Universe}

This investigation will be carried out on IES workers (administrative, quartermaster, crew)

\subsection{Sample Size and Type}

The population is made up of 80 administrative and teaching workers (unionized, non-unionized, for fees and crew) who carry out administrative activities. 
It is a probabilistic sample for convenience according to the characteristics, time and resources, destined to the present investigation.

The type of research used in this present work is: descriptive, field and correlated.

The research design is Non-Experimental.

\subsection{Definition of Variables}

Dependent variable. Work commitment directly influences training

Independent variable. Training

\subsection{Hypothesis}

Training positively influences the work commitment of the administrative staff of a Higher Education Institution

\section{Results}

A questionnaire was made to the personnel of the Institution of Higher Education, considering a total of 80 workers between administrative and teachers with administrative burden, answering a total of 22 questions that cover the topics of training and commitment, in order to develop the concepts to be come to consider them as factors that generate work commitment in the human capital of the institution.

\section{Study design}

\section{Instrument}

Questionnaire with likert scale questions

Information processing

\begin{tabular}{|c|c|c|c|c|c|c|c|c|c|c|}
\hline & ঐ্ & $\begin{array}{l}\frac{8}{7} \\
\text { 인 }\end{array}$ & 这 $\overline{\bar{z}}$ & 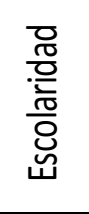 & 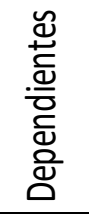 & 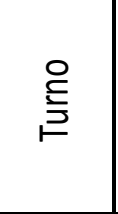 & $\begin{array}{l}\frac{\tilde{0}}{0} \\
\text { 호 }\end{array}$ & 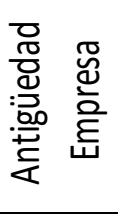 & 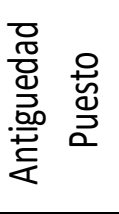 & 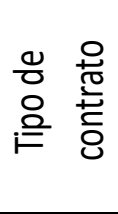 \\
\hline 1 & $17 \%$ & $11 \%$ & $39 \%$ & $0 \%$ & $61 \%$ & $100 \%$ & $0 \%$ & $28 \%$ & $44 \%$ & $17 \%$ \\
\hline 2 & $83 \%$ & $44 \%$ & $39 \%$ & $6 \%$ & $39 \%$ & $0 \%$ & $94 \%$ & $17 \%$ & $17 \%$ & O\% \\
\hline 3 & & $28 \%$ & $11 \%$ & $17 \%$ & $0 \%$ & $0 \%$ & $6 \%$ & $28 \%$ & $22 \%$ & $17 \%$ \\
\hline 4 & & $17 \%$ & $11 \%$ & $22 \%$ & $0 \%$ & $0 \%$ & $0 \%$ & $28 \%$ & $17 \%$ & $61 \%$ \\
\hline 5 & & & & $33 \%$ & & & & & & $6 \%$ \\
\hline 6 & & & & $22 \%$ & & & & & & \\
\hline
\end{tabular}

\section{FINDINGS:}

$>$ The number of men in relation to women is represented by $83 \%$ of them.

$>$ The administrative activities of the HEI, mostly administrative activities, show that women do the most work in the departments.

$>$ More than $40 \%$ of the people who work within the ies facilities have an age range between 26 to 40 years.

$>$ This shows us that people with administrative activities are young adults with recent knowledge.

$>$ Same percentage in personal relationships for married and single. (39\%)

$>$ It allows you to know your personal information and determine the values of the courses and your direction for the training as well as your commitment to the heis

$>$ The administrative staff meets several of the skills and knowledge to develop positions at desks, since it is made up of many personnel with high intellectual capacity, it is possible to take courses for these. 
$>$ The perspective of colleagues on others about the appropriate work and the function they perform indicates a lack of critical capacity to determine if training is lacking.

$>$ The result of this graph shows us that at least $28 \%$ of the staff is satisfied with the knowledge about their functions. They do not denote interest in wanting to take courses.

$>$ More than half of the workers $(66 \%)$ consider that, if there are training needs, they detect that the functions are not well done or established.

$>$ They confuse the training program at the general institutional level (All the work center by the faculties) with the one that may exist in the Faculty (72\%).

$>28 \%$ consider that it is useless to carry out training

$>72 \%$ of workers consider personal development to be an important part of their training, which can be considered a point of motivation for their commitment.

$>50 \%$ of the staff consider that all receive the same possibilities of being able to take a course that allows them to improve their skills within the institution, the other half want greater opportunities.

$>$ The attachment felt by some of the collaborators within the institution is evident, since out of more than half they find that sense of pleasure that in the end can be called commitment.

$>$ For all workers, only $22 \%$ in some cases do not consider their work satisfactory within the area where they are working.

$>$ For the worker, within the events that take place in the institution not all put the same effort, therefore not all consider themselves committed.

$>$ There is a debt on the part of the authority so that the worker feels motivated to do his best, since at least $50 \%$ say that his work is occasionally or not recognized.

$>$ This is a key point so that the worker, in addition to feeling motivated by the place where he works, also continues to improve since the environment shows collaboration in the events.

$>$ Not all staff feel the pleasure of going to work at the institution, we are talking about $50 \%$ unless they frequently feel comfortable and the rest not always.

$>$ Only $39 \%$ percent of the total is considered to be able to give their opinion in some decisions.

$>$ The climate or work environment is very important in the IES, that is why they consider that they are helped and the improvement of the environment is taken into account.

\section{DISCUSSION}

These factors that are shown to develop commitment within higher education institutions are anchored in the fulfillment of the objectives that are set, but that are shown from their affective or emotional way towards the place where they are, working with colleagues and goals to reach. Both the emotional sense and the preparation that are given by the training courses, which are key for the workers to bear fruit and demonstrate that there will be a reciprocity between the individual and the organization as a response to these factors generating that commitment towards their Institution. Higher Education.

\subsection{Checking the Hypothesis}

Hypothesis. Training positively influences the work commitment of the administrative staff of a Higher Education Institution.

The fact that there are many training methods that are presented to IES workers, and they are continuously promoting these through the different means of information both physical (documents, calls, trades, paper) and electronic (social networks) and be aware of the offer of these, it does not generate an obligation in itself to participate in the process of personal improvement, those who take them are by a re-category, however it is a completely different issue. Here it is observed that the fact that there are training courses does not influence the commitment of all the personnel within the Institution of Higher Education. Therefore, the hypothesis is not fulfilled as it is not reflected. 


\section{CONCLUSION}

The worker who wishes to grow and improve must do so of his own free will, if he feels comfortable where he is working. Part of this we can add that there may be a sense of belonging where their needs have been detected to improve their functions and activities within their workplace. When they decide that they want to continue growing and the opportunities for their work in this case, the Higher Education Institution allows them to clarify and improve in an accessible way so that in addition to learning a trade or specialty or workshop, when taken into account they can choose to continue in this area of continuous improvement. This will be reflected in your daily role.

Seeing the growth of refresher or training courses, the worker could now feel a commitment to the institution by providing tools or study methods that allow constant personal and productive improvement for his person.

\section{Proposals}

1. Identify the needs of workers in terms of training

2. Carry out a diagnosis of training needs and provide it as far as possible

3. Assign a motivating leader to carry out the training courses

4. That workers propose their own training courses

5. It is essential that the functions of the leader establish the professional development of the collaborators to generate belonging, empowerment, commitment and loyalty

\section{REFERENCES}

[1] Siliceo, A. (2006). Training and staff development. Editorial Limusa.

[2] Rodríguez, M. and Catherine P. (2010), El Programa Nacional de Formación y Capacitación Permanente (Pronafcap). Education Vol. XIX, N ${ }^{\circ}$ 37, September 2010, pp. 87-103 / ISSN 1019-9403

[3] DEMING, W. E., (1989). Quality, productivity and competitiveness. The way out of the crisis, Madrid: Díaz de Santos

[4] Jurán, J. M. and Gryna, F.M. (1994). Analysis and quality planning. 3rd. Ed. McGraw Hill

[5] De Frutos, B., Ruiz, M. \& San Martín, R. (1998). Confirmatory factor analysis of the dimensions of commitment to the organization. Autonomous University of Madrid.

[6] Meyer, J.P. \& Allen, N.J. (1997). Commitment in the workplace: Theory, research and application. London: Sage publications.

[7] Alles, M. A. (2004). Strategic management of human resources. Management by competencies. Buenos Aires- Mexico: Granica.

[8] Other sources consulted:

[9] Gatewood, R. (1990). Human Resources Selection, Second Edition, Dryden

[10] Galicia, Fernando A (1991). Human Resources Administration, 4th edition.

[11] Stephen Robbins (2000). Administration in Today's World

[12] Gatewood, R. (1990). Human Resources Selection, Second Edition, Dryden

[13] Sherman Arthur (2001). Human Resources Administration, Training and Development. Developing Human ResourceEffectiveness, 12th Edition. 2001 p.216 


\section{AUTHORS' BIOGRAPHY}

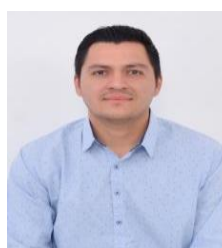

\section{Josede Jesús Hernandez Sanchez}

Degree in Administration

Mail: jose.hernandez.sanchez@uaq.edu.mx

Lic. in administration faculty of accounting and administration of the autonomous university of Querétaro (2006-2010) degree.

Specialist in management of the human factor

Specialist in business and international trade

Student of Master's degree in administration (currently) at the faculty of Accounting and Administration at the Autonomous University of Querétaro

FCA Academic Mobility Coordinator (current)

Teacher of the bachelor's degree in administration in the 6th semester, subject individual and collective labor relations (current), sustainable development subject 8th semester virtual modality (current)

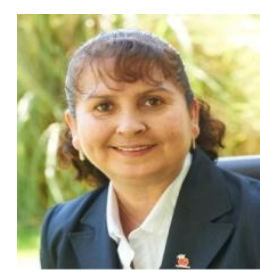

Dr. Josefina Morgan Beltrán, Research Professor of the Autonomous University of Querétaro, head of the postgraduate division of the Faculty of Accounting and Administration, Doctor of Administration with post-doctorate in Education, member of the National System of Researchers level I (SNI), member of the Program for Professional Development Teacher (PRODEP) and the National Association of Accounting and Administration Faculties and Schools (ANFECA).

Citation: José de Jesús Hernández Sánchez, et. al., "Factors that Generate Labor Commitment in the Human Capital of an Institution of Higher Education" International Journal of Managerial Studies and Research (IJMSR), vol 9, no. 4, 2021, pp. 32-39. doi: https://doi.org/10.20431/2349-0349.0903004.

Copyright: (C) 2021 Authors. This is an open-access article distributed under the terms of the Creative Commons Attribution License, which permits unrestricted use, distribution, and reproduction in any medium, provided the original author and source are credited. 